\title{
ISOLATION AND CHARACTERIZATION OF SARUBICIN A, A NEW ANTIBIOTIC
}

\author{
G. Reinhardt, G. Bradler, K. Eckardt, ${ }^{*}$ D. Tresselt and W. IhN \\ Akademie der Wissenschaften der DDR, Forschungszentrum für Molekularbiologie \\ und Medizin, Zentralinstitut für Mikrobiologie und Experimentelle Therapie, \\ DDR-69 Jena, Beutenbergstraße 11, DDR
}

(Received for publication May 30, 1980)

\begin{abstract}
The new antibiotic sarubicin A [red crystals, mp. $194 \sim 195^{\circ} \mathrm{C}, \mathrm{C}_{13} \mathrm{H}_{14} \mathrm{~N}_{2} \mathrm{O}_{6}$ (I)] was isolated from fermentations of a Streptomyces strain. The compound is moderately active in vitro against Micrococcus luteus.
\end{abstract}

An antibiotic, designated sarubicin $\mathrm{A}^{* *}$ was isolated from the culture filtrate of Streptomyces strain JA 2861. On the basis of taxonomic studies the producing strain was found to be related to Streptomyces violaceoruber. The present communication describes the isolation of crystalline sarubicin A and its chemical and biological characteristics.

\section{Experimental}

Fermentation procedure for production of sarubicin complex

Streptomyces strain JA 2861, resulted from a screening program and stored in the lyophilized state was used for fermentation. For short-term maintenance the culture was grown to sporulation for 10 12 days at $28^{\circ} \mathrm{C}$ on agar slants consisting of $0.3 \%$ saccharose, $1.5 \%$ dextrin, $0.01 \%$ carbamide, $0.1 \%$ yeast extract, $0.5 \%$ Bacto Pepton "Difco", $0.05 \% \mathrm{NaCl}, 0.05 \% \mathrm{KH}_{2} \mathrm{PO}_{4}, 0.001 \% \mathrm{FeSO}_{4} \cdot 7 \mathrm{H}_{2} \mathrm{O}, 3.0 \%$ agar-agar, $\mathrm{pH} 6.8 \sim 7.0$, and then kept at $4^{\circ} \mathrm{C}$.

The following seed stage medium was found to be useful to produce a vegetative inoculum: $1.5 \%$ glucose, $1.5 \%$ soya bean meal, $0.5 \% \mathrm{NaCl}, 0.1 \% \mathrm{CaCO}_{3}, 0.03 \% \mathrm{KH}_{2} \mathrm{PO}_{4}, \mathrm{pH} 6.8$. A spore suspension was used to inoculate this medium and was incubated for 48 hours at $28^{\circ} \mathrm{C}$ on a rotary shaker. The vegetative mycelium of the seed stage was used to inoculate the fermentation medium consisting of $2 \%$. glucose, $1 \%$ soya bean meal, $0.5 \% \mathrm{NaCl}, 0.3 \% \mathrm{CaCO}_{3}, 0.5 \%$ solids of corn steep liquor, $\mathrm{pH} 6.8$, and incubated for $3 \sim 4$ days at $28^{\circ} \mathrm{C}$.

Shake flask seed and final fermentation were carried out on the laboratory scale in 500-ml cylindrical culture flasks containing $80 \mathrm{ml}$ of medium and incubated at $28^{\circ} \mathrm{C}$ on a rotary shaker at $180 \mathrm{rpm}$ and with a throw of $45 \mathrm{~mm}$. Pilot scale fermentations were carried out in glass and stainless-steel fully baffled stirred fermenters, respectively. A seed stage using the medium described was inoculated with a spore suspension and incubated at $28^{\circ} \mathrm{C}$ for 48 hours. Final fermentations were carried out in fermenters containing 20 or 450 liters of the described medium inoculated with $5 \%$ of vegetative seed growth and cultured at $28^{\circ} \mathrm{C}$ for $3 \sim 4$ days. Seed and final fermentations were carried out with an agitation rate of $300 \mathrm{rpm}$ and an air flow rate of $1.0(\mathrm{vol} / \mathrm{vol}) / \mathrm{min}$.

The production of sarubicin complex was followed by a hole plate diffusion method with Micrococcus luteus (Sarcina lutea SG 125A) as the test organism.

Isolation of the antibiotic

The culture filtrate of harvested mash was extracted at pH 4.0 with 0.3 volume of $n$-butanol. After

** In a preliminary short communication ${ }^{1)}$ this antibiotic was named sarcinamycin A on its specific activity against Sarcina lutea. The term of the test organism has been revised to Micrococcus luteus. To avoid misunderstandings we felt it necessary to introduce the new name sarubicin A for the antibiotic. 
evaporation of the extract the crude concentrate was chromatographed on aluminium oxide (activity of aluminium oxide was reduced by addition of $10 \%$ of water). The material was eluted with chloroform followed by further elution with butanol. A red active substance crystallized from the main red fraction. The compound was then chromatographed on a silica gel column $\left(\mathrm{KH}_{2} \mathrm{PO}_{4}\right.$-buffered silica gel ${ }^{2}$, $30 \times 3 \mathrm{~cm}$ ). Elution was with ethyl acetate. The main red band was accompanied with two minor yellow bands. The red fractions of several columns were combined and concentrated to a small volume. After cooling crystalline sarubicin A was obtained. Analytically pure substance was prepared by recrystallization from ethyl acetate.

\section{Analytical procedure}

Antibiotic activity (MIC) was determined by the agar plate diffusion method with different test organisms. Purified samples were dissolved in methanol and diluted with water.

\section{Results}

Physical and Chemical Properties

Sarubicin A is a red crystalline antibiotic which is soluble in lower alcohols, acetone, chloroform, and other common organic solvents. It is less soluble in water. In concentrated $\mathrm{H}_{2} \mathrm{SO}_{4}$ the antibiotic dissolves with yellow colour. Crystals of sarubicin A melt at $194 \sim 195^{\circ} \mathrm{C}$. Elementary analysis gave $\mathrm{C}, 52.91 ; \mathrm{H}, 4.64 ; \mathrm{N}, 9.17 \%$. $\mathrm{C}_{13} \mathrm{H}_{14} \mathrm{~N}_{2} \mathrm{O}_{6}$ requires $\mathrm{C}, 53.06 ; \mathrm{H}, 4.76 ; \mathrm{N}$, $9.50 \%$. The ultraviolet and visible absorption spectrum of sarubicin A in chloroform contains maxima at 262, (286), and $498 \mathrm{~nm}(\log \varepsilon 4.10$, (3.88), 3.20) (Fig. 1). The infrared spectrum (Fig. 2) in $\mathrm{KBr}$ had characteristic absorptions at 1605 and $1645 \mathrm{~cm}^{-1}$.

Structure I (Fig. 3) has been deduced from detailed studies of sarubicin $\mathrm{A}$ and its monoacetate. ${ }^{3)}$

\section{Biological Properties}

The agar plate diffusion method was used to determine the antibacterial activity. Sarubicin A is active against Micrococcus luteus but is not or only slightly active against other strains of

Fig. 1. UV spectrum of sarubicin $\mathrm{A}$ in chloroform.

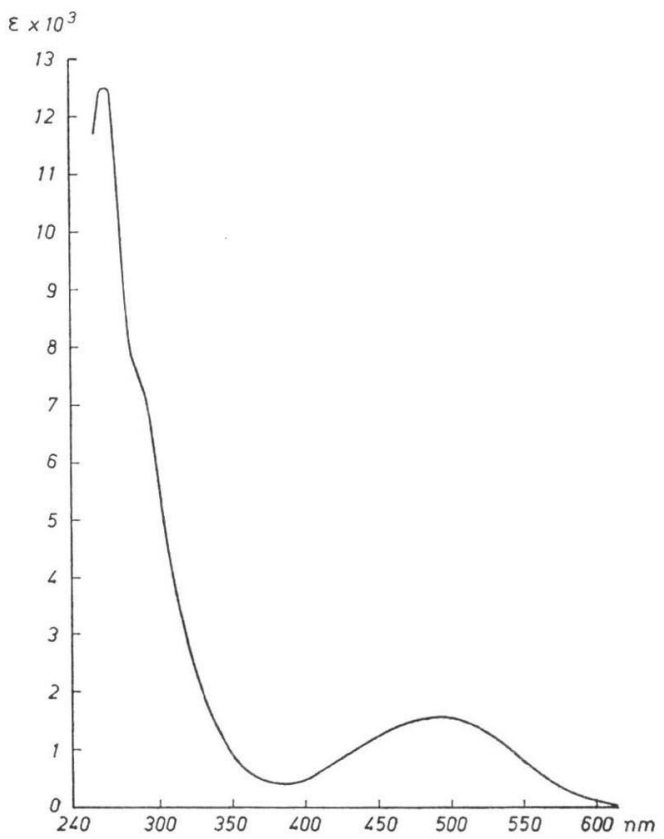

bacteria tested (Table 1). It did not inhibit the growth of yeasts and fungi tested.

\section{Discussion}

The Streptomyces strain JA 2861 was found to produce a mixture of new antibiotically active pigments. The main component designated as sarubicin A was isolated as red crystals. Structural elucidation studies of this compound, details of which will be published elsewhere ${ }^{32}$, have indicated that sarubicin A has structure I. On the basis of these results and its physico-chemical as well as biological characteristics sarubicin A was found to be a new antibiotic. Its chemical structure shows some interesting relations to the structures of granaticin and granaticin $\mathrm{B}^{4,5)}$, dihydrogranaticin ${ }^{6)}$, and granaticinic $\operatorname{acid}^{7)}$. 
Fig. 2. IR spectrum of sarubicin $\mathrm{A}$ in $\mathrm{KBr}$.

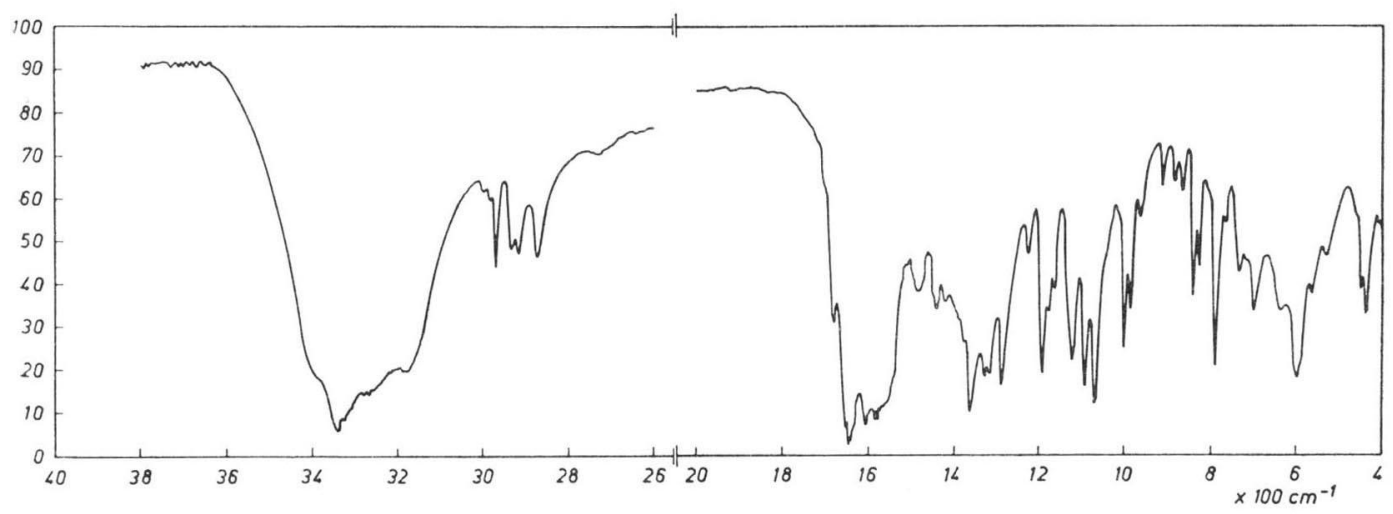

Table 1. Antimicrobial activity of sarubicin A (agar plate diffusion test).

\begin{tabular}{l|r}
\hline \multicolumn{1}{c|}{ Test organism } & MIC $\mu \mathrm{g} / \mathrm{ml}$ \\
\hline Bacillus subtilis ATCC 6633 & $>100$ \\
Bacillus globifer OH 11 & 100 \\
Bacillus mycoides SG 756 & $>100$ \\
Staphylococcus aureus SG 511 & 100 \\
Micrococcus luteus & 15 \\
(Sarcina lutea SG 125A) & $>100$ \\
Escherichia coli mutabile SG 458 & 50 \\
Escherichia coli C 600 & $>100$ \\
Proteus vulgaris Ox 19 SG 2 & $>100$ \\
Klebsiella aerogenes SG 117 & 25 \\
Alcaligenes faecalis ATCC 8750 & 50 \\
Comamonas terrigena ATCC 8461 & $>100$ \\
Mycobacterium phlei SG 346 & \\
\hline
\end{tabular}

In concentrations of $100 \mu \mathrm{g} / \mathrm{ml}$ sarubicin A did not inhibit the growth of yeasts and fungi tested.

Fig. 4. Mass spectrum of sarubicin A.

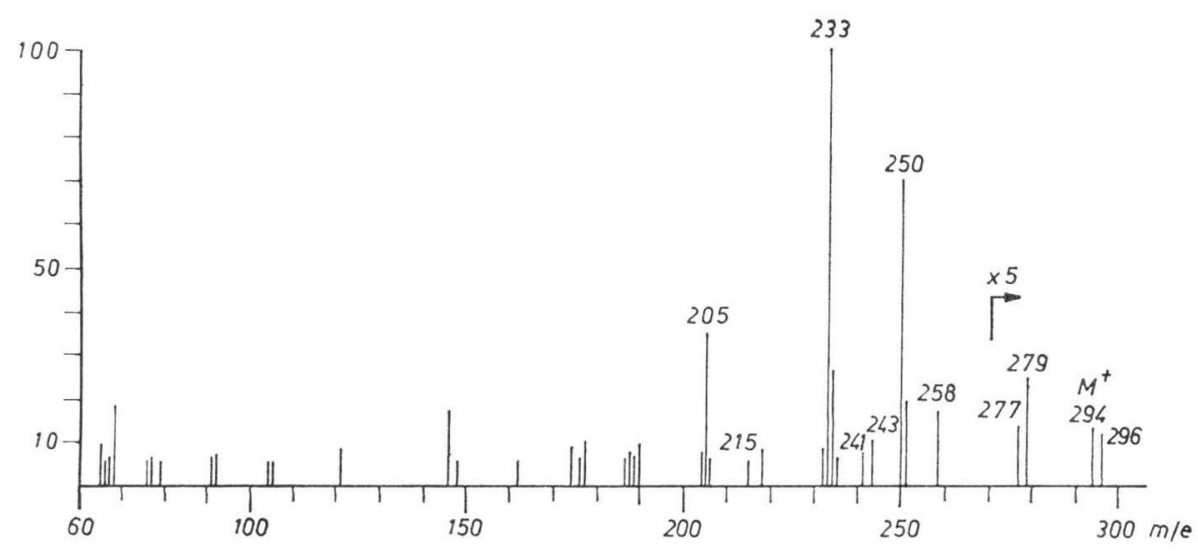




\section{References}

1) Reinhardt, G.; G. Bradler, D. Tresselt, W. Ihn, L. Radics \& K. Eckardt: Sarcinamycin A, a new antibiotic. Abstracts Int. Symp. Antibiotics, Weimar, GDR, B-31, 1979

2) Eckardt, K.; D. Tresselt \& W. Ihn: Antibiotika aus Actinomyceten. Zur chemischen Konstitution des Antibiotikums Griseorhodin A. I. Isolierung und Struktur von zwei Abbauprodukten. Tetrahedron 34: 399 404, 1978

3) Tresselt, D.; K. Eckardt, W. Ihn, L. Radics \& G. Reinhardt: Zur chemischen Konstitution des Antibiotikums Sarubicin A. Tetrahedron (London) in preparation

4) Keller-Schierlein, W.; M. Brufani \& S. Barcza: Stoffwechselprodukte von Mikroorganismen. 141. Die Struktur des Granaticins und des Granaticins B. I. Spektroskopische Eigenschaften und chemischer Abbau. Helv. Chim. Acta 51: 1257 1268, 1968

5) Brufani, M. \& M. Dobler: Stoffwechselprodukte von Mikroorganismen. 142. Die Struktur des Granaticins und des Granaticins B. II. Die Kristallstruktur des Tri-O-acetyl-O-jodacetyl-granaticins. Helv. Chim. Acta 51: 1269 1275, 1968

6) Pyrek, J. St.; O. Achmatowicz, Jr. \& A. Zamojski: Naphtho- and anthraquinones of Streptomyces thermoviolaceus WR-141. Structures and model syntheses. Tetrahedron 33: 673 680, 1977

7) Maehr, H.; H. v. Cuellar, J. Smallheer, Th. H. Williams, G. J. Sasso \& J. Berger: Microbiol products. II. Granaticinic acid, a new antibiotic from a thermophilic streptomycete. Monatsh. Chem. 110: 531 540, 1979 